\title{
Contrasting Growth Rate Patterns in Eighteen Tree Species From a Post-Hurricane Forest in Nicaragua'
}

\author{
John Vandermeer², Iñigo Granzow de la Cerda \\ Department of Biology, University of Michigan, Ann Arbor, Michigan 48109, U.S.A. \\ and
}

Douglas Boucher

Appalachian Environmental Laboratory, University of Maryland, Frostburg, Maryland, U.S.A.

\begin{abstract}
Hurricane Joan struck the Caribbean Coast of Nicaragua in October 1988 causing extensive damage to the lowland rain forest of the zone. Six permanent plots were established in 1990 and the growth rates of all individuals in a total area of $6000 \mathrm{~m}^{2}$ monitored for six years. Eighteen of the species were abundant enough to measure species-specific growth rates. The post hurricane successional process included a great deal of resprouting of pre-existing individuals and the current state of the forest includes a low but very dense canopy, suggesting that competition is entering an intensive phase. Specific growth rates between the time of the hurricane and the present thus represent establishment or regenerative growth rates and provide an indication of whether or not distinct regeneration niches exist. Three distinct patterns of growth rate seem apparent, fast-growing heliophyles (eight species), slow-growing resprouters (nine species), and Vochysia ferruginea, which seems to have a special pattern.
\end{abstract}

Key words: lowland rainforest; Nicaragua; niche theory; post-hurricane succession; regeneration strategies; tree growth rutes.

THE ROLE OF PERIODIC DISTURBANCE HAS LONG BEEN recognized in ecology as an important organizing force (Sousa 1984, Pickett \& White 1985, Mooney \& Gordon 1983, Miller 1982). In particular, catastrophic wind damage is known to be a strong determining force in many temperate forests (Spurr 1956, Canham \& Loucks 1984, Dunn et al. 1983, Flanagan 1988). Since hurricanes (or typhoons or cyclones) are more frequent in tropical areas, it is natural to expect them to be even more important in structuring tropical forests. Recent observations corroborate such an expectation (Yih et al. 1991, Vandermeer et al. 1990, Frangi and Lugo 1991, Walker 1991, Brokaw \& Grear 1991, Reilly 1991).

The process of post disturbance forest succession has been conveniently codified as a two variable dynamic model (Vandermeer 1994). The two variables of interest are total biomass (B) and number of species (S). Immediately after the disturbance, both variables are reduced, the amount of reduction proportional to the severity of the disturbance. Subsequently both variables begin to increase, but $S$ increases much faster than $B$. This is

${ }^{1}$ Received 14 September 1995; accepted 17 November 1995.

${ }^{2}$ Correspondence address: John Vandermeer, Department of Biology, University of Michigan, Ann Arbor, Michigan, U.S.A. 48109, FAX 313-747-0884 e-mail john.vandermeer@um.cc.umich.edu the "building phase" of succession, in which new individuals thrive in the relatively competition-free space created by the disturbance. Once the canopy is filled, and/or the nutrient base depleted, new individuals encounter difficulty entering the community, and the process of competitive thinning begins. Competitive thinning reduces the number of individuals, and, by implication, the number of species, until competitive equilibrium is reached (Vandermeer 1994).

A recent theory of rain forest diversity rests on the assumption that most species of rain forest trees are effectively neutral (Hubbell \& Foster 1986). This point of view is reflected in a growing literature on the nature of so-called lottery competition (Chesson \& Warner 1981) and summarized in a recent paper with the telling title "Do Plants Need Niches" (Silvertown \& Law 1987) which provides the tentative answer, maybe not. On the other hand Grubb (1977) provided substantial evidence that different species occupy different niches with regard to capacity for regeneration or establishment. Grubb's (1977) work suggests that even if different niches did not exist for trees after they become part of an old growth canopy, during earlier stages of growth and/or succession different niches could be important in setting the stage for future competitive exclusion. Thus, for example, even if two species are competitively equal when 
TABLE 1. Species included in the study. $I=$ Fonseca, $I I=$ Bodega.

\begin{tabular}{llll}
\hline \multicolumn{1}{c}{ Species } & Site & \multicolumn{1}{c}{ Habitat } & \multicolumn{1}{c}{ Dispersal } \\
\hline Croton smithianus & I \& II & Large pioneer & Explosive capsule \\
Cupania glabra & I \& II & Subcanopy & Bird? \\
Dendropanax arboreus & I \& II & Canopy & Bird? \\
Guatteria sp. & I \& II & Small subcanopy & Bird \\
Isertia hankeana & I \& II & Small subcanopy & Bird \\
Miconia prasina & I \& II & Subcanopy & Bird \\
Rinorea hummelii & I \& II & Canopy & Bird \\
Vochysia ferruginea & I \& II & Canopy & Wind \\
Cecropia obtusifolia & I & Large pioneer & Bird, Bat \\
Galipea granulosa & I & Small subcanopy & Explosive capsule \\
Goethalsia meiantha & I & Canopy & Wind \\
Manilkara zapota & I & Canopy & Bird? \\
Byrsonima crasifolia & II & Subcanopy & Bird \\
Casearea arborea & II & Subcanopy & Bird? \\
Lacistema agreggatum & II & Subcanopy & Bird \\
Pseudolmedia spuria & II & Subcanopy & Bird \\
Qualea parense & II & Canopy & Wind \\
Vismia macrophylla & II & Small subcanopy & Bird \\
\hline
\end{tabular}

they reach the canopy, if one species reaches the canopy on average more quickly than another, its chances of being in a competitively superior position in that canopy are clearly enhanced.

The landfall of Hurricane Joan in Nicaragua in October 1988 provided an opportunity to examine the immediate response of the forest to this catastrophic event, and to investigate whether or not distinct establishment niches exist. Early documentation of this process (Vandermeer et al. 1990, Yih et al. 1991, Boucher 1992) emphasized the strong capacity of damaged trees to resprout, and the apparent rapid growth of advanced regeneration in the form of saplings (Vandermeer et al. 1995). Six years after the event a very dense canopy had developed from the resprouts and pre-existing saplings. This new canopy has formed approximately eight to ten meters above the ground and appears to be relatively continuous. The forest thus seems to be entering a new phase in which the earlier "building" phase is now giving way to a "thinning" phase. Therefore, these first six post hurricane years can be thought of as the building or establishment phase of the particular successional process under way, and if different regeneration niches exist, it is during this period that they should be observable.

The individuals in the current low-lying canopy will initiate the new phase of competition, and all growth between the time of the hurricane and the present can be thought of as establishment growth, reflecting a "regeneration niche" (Grubb 1977). To what extent can we identify, during this establishment phase, different life styles, niches in a broad sense, among the more common species of trees? In this paper we present growth data for eighteen tree species for a six year period following landfall of Hurricane Joan.

\section{METHODS}

The general study area is approximately 500,000 ha surrounding Bluefields, on the Caribbean Coast of Nicaragua, effectively the area damaged by Hurricane Joan. This is an area of high rainfall with a relatively distinct dry season extending from approximately mid-January through mid-May. The vegetation is mainly lowland tropical rain forest, of the general type that occurs throughout the Caribbean coast of Central America from Belize to Panama. Extensive swamp forests also occur throughout the area, as well as the southern extent of the Caribbean pine savannas. All plots in this study were located in rain forest habitat. While no complete soil analyses have been completed in the study area, general soil maps and casual observation suggest that the soils are ultisols.

Two sites were chosen within the hurricane affected area, one near what seemed to be the edge of the damaged area (Fonseca), and one almost directly in the center of the damaged area (Bodega). Three line transects $(100 \mathrm{~m} \times 10 \mathrm{~m})$ were set up in each of the two areas in 1990 . All trees greater than $3.18 \mathrm{~cm}$ in diameter (10 cm circumference) were located, tagged with a numbered aluminum tag affixed with an aluminum nail, and their diameters at breast height measured. A spray paint 

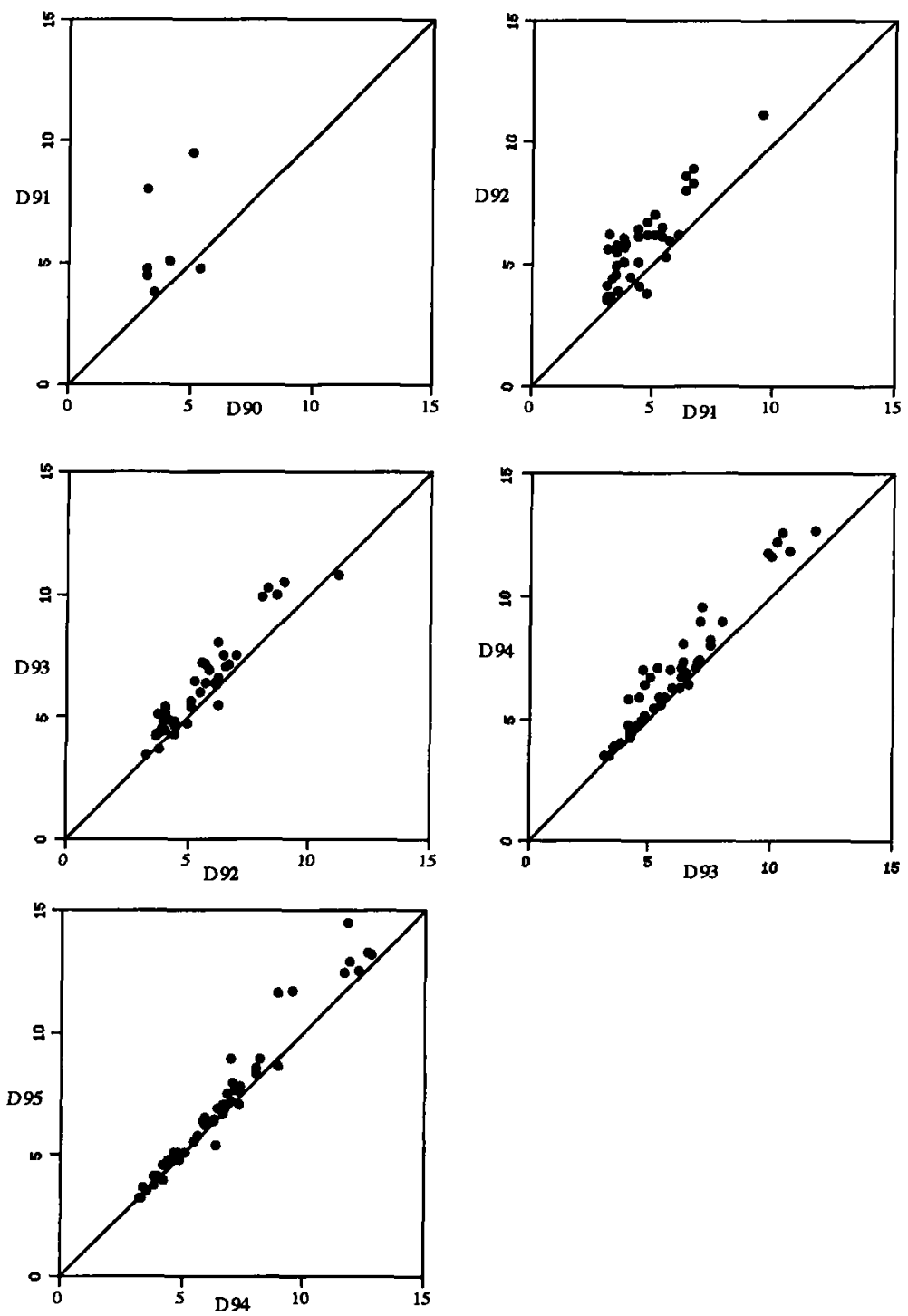

FIGURE 1. Yearly changes in diameter at breast height for Goethalsia meiantha from Fonseca. The $\mathrm{x}$ axis represents diameter (D) measures at a particular year (e.g., 90 represents 1990) and the y axis represents diameter measures one year later. The five yearly changes are thus represented on five separate graphs.

mark indicated the position of the measurement for future years, and voucher specimens of all species were prepared and deposited in the National Herbarium of Nicaragua, the University of Michigan Herbarium, and the National Institute of Biodiversity in Santo Domingo, Costa Rica. Data were collected as circumferences and later translated into diameter measurements.

In these two sites, amongst the almost 200 species of trees encountered in all transects, we have identified eighteen species that are common enough to obtain some aggregate data. In Table 1 we list those species, with other relevant information.

Basic growth performance can be easily visualized on a graph of diameter in year $t+1$ versus the diameter of that same tree in year $t$. No change in diameter will result in a point directly on the $45^{\circ}$ line, and a positive growth rate will be indicated by a point above the $45^{\circ}$ line. Such plots were constructed for all species at appropriate sites.

Yearly diameter growth can be conveniently 

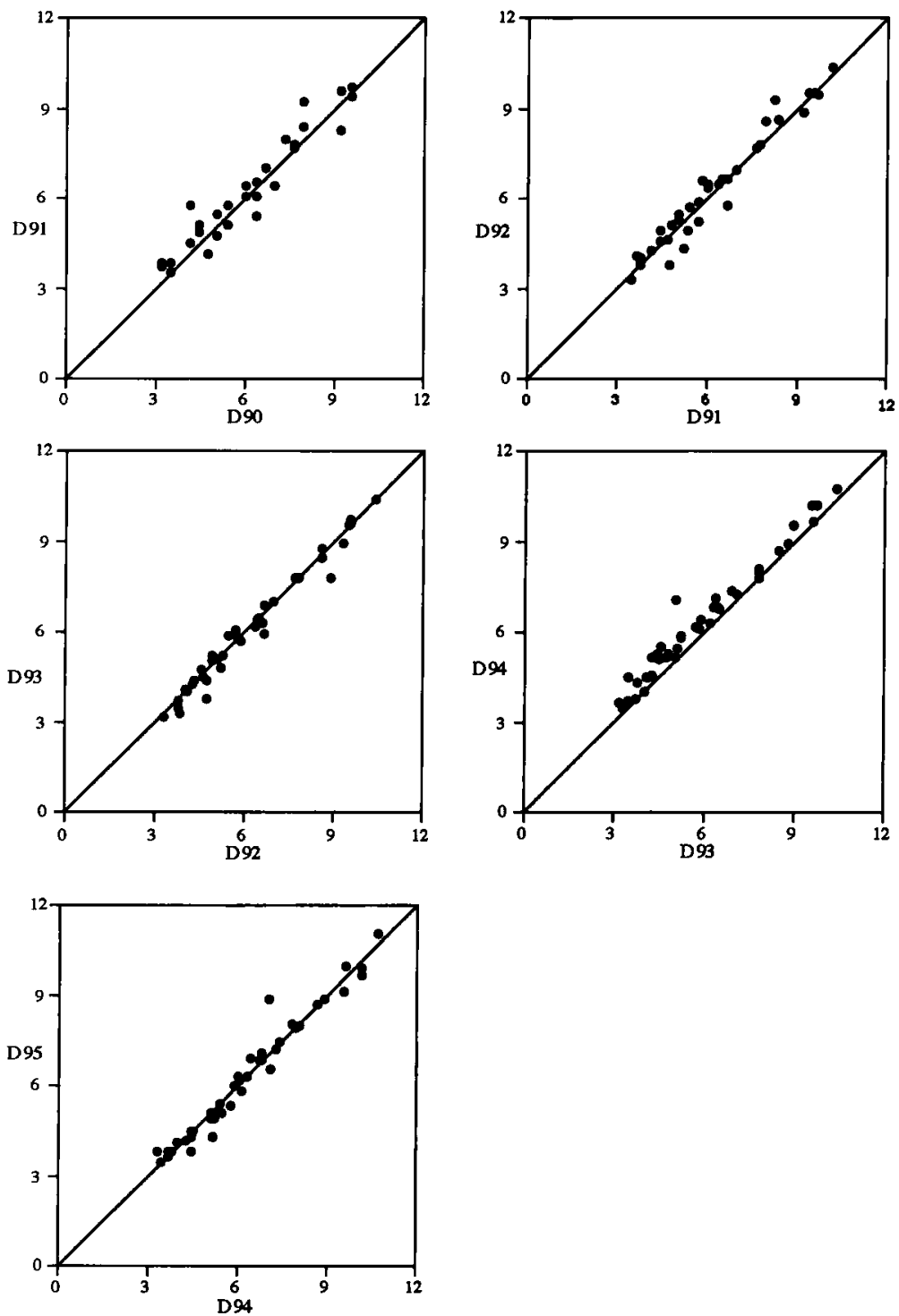

FIGURE 2. Yearly changes in diameter at breast height for Galipea granulosa from Fonseca.

measured as percent change in diameter. That is if $X(t)$ is the diameter in year $t$, and $X(t+1)$ the diameter in year $t+1$, we take as a definition of growth, $\mathrm{b}=\mathrm{X}(\mathrm{t}+1) / \mathrm{X}(\mathrm{t})$, or $\mathrm{X}(\mathrm{t}+1)=\mathrm{bX}(\mathrm{t})$. Thus, a regression of $X(t+1)$ versus $X(t)$, setting the intercept at zero, provides an estimate of $b$, the average rate of growth between $t$ and $t+1$. Such regressions were carried out for all eighteen species, at appropriate locations, for the time periods $1990-91, \quad 1991-92,1992-93,1993-94$, and 1994-95. Values were converted into the more traditional relative growth rate (RGR) by the formula $\mathrm{RGR}=\mathrm{b}-\mathrm{l}$.

\section{RESULTS}

In Figure 1 we display the raw data for Goethalsia meiantha from Fonseca. In Figure la the rapid average growth rate is clearly seen reflected in the deviation of most of the points from the $45^{\circ}$ line. Proceeding from Figure 1a through $1 \mathrm{~b}, 1 \mathrm{c}, 1 \mathrm{~d}$, and $1 \mathrm{e}$, the growth rates from succeeding years are similarly displayed. The general pattern is clear. Beginning with a very rapid growth rate in 1990-1991, presumably owing to the opening up of the forest as a result of the hurricane, the population proceeds with decreasing growth rates in successive 

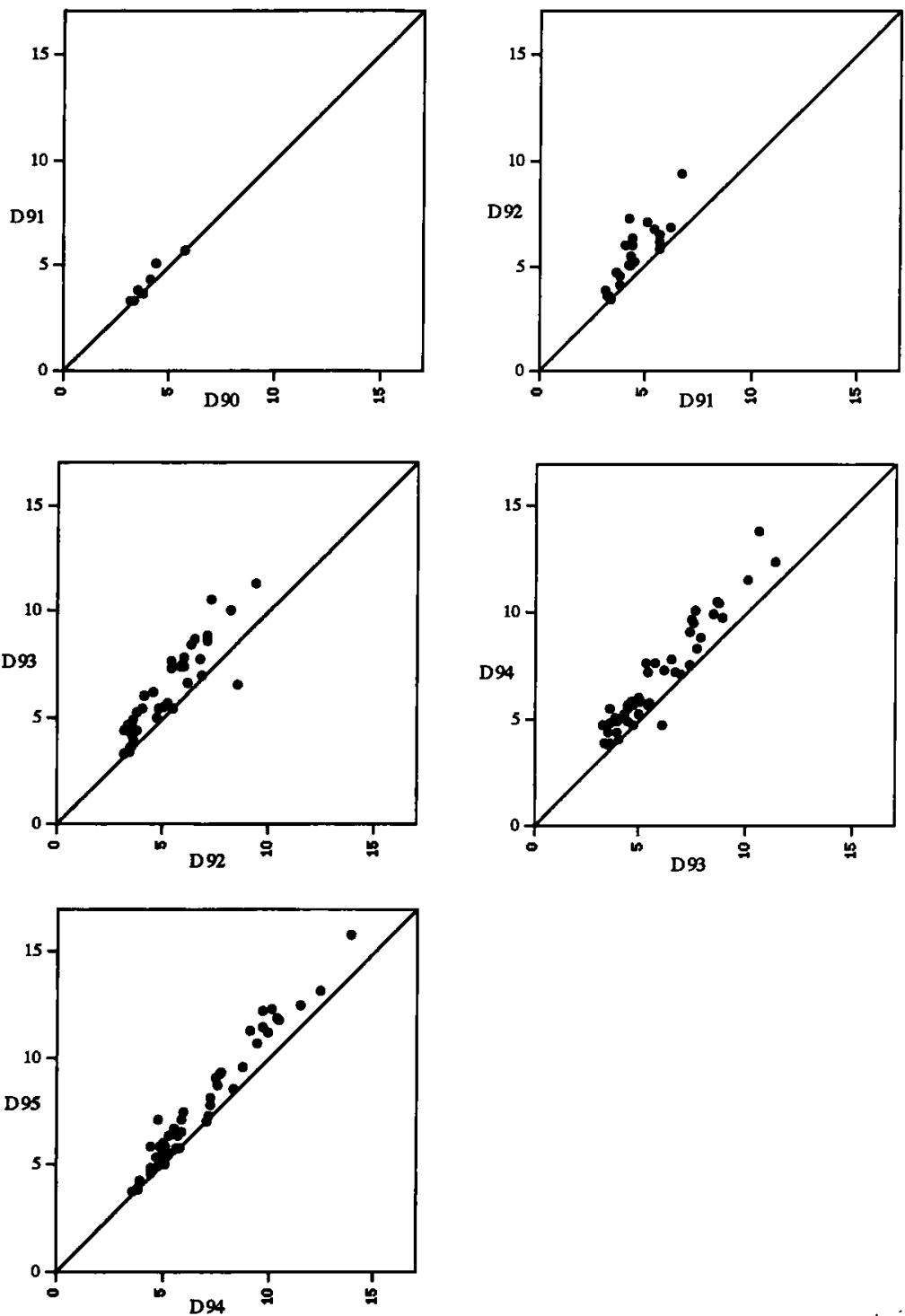

FIGURE 3. Yearly changes in diameter at breast height for Croton smithianus from Fonseca.

years, presumably owing to the gradual closing of the canopy of the forest. Thus, there is an obvious deviation of the points from a $45^{\circ}$ line in the year ending in 1991 and the closer packing of the points near the $45^{\circ}$ line in the year ending in 1995.

In Figure 2 we display the raw data for Galipea granulosa from Fonseca. This species is known locally as "Yankee's foot" (pata de yanke) because of its extremely hard wood, implying a physiologically fixed slow growth rate and possible inability to respond effectively to the increased light environment afforded by the hurricane. Such an expectation is reflected in the growth data (Fig. 2). All points for all years are tightly concentrated near the $45^{\circ}$ line.

In Figures 3 and 4 we illustrate two similar species from Bodega, Croton smithianus and Rinorea sp. The former is a pioneer, dispersed with an explosive capsule and well-known locally for its rapid growth and soft wood, while the latter is a subcanopy bird-dispersed tree that resprouted massively subsequent to the hurricane (Vandermeer et al. 1995). The two patterns previously noted are clearly reflected in these two species also.

Finally in Figure 5 we illustrate the common 

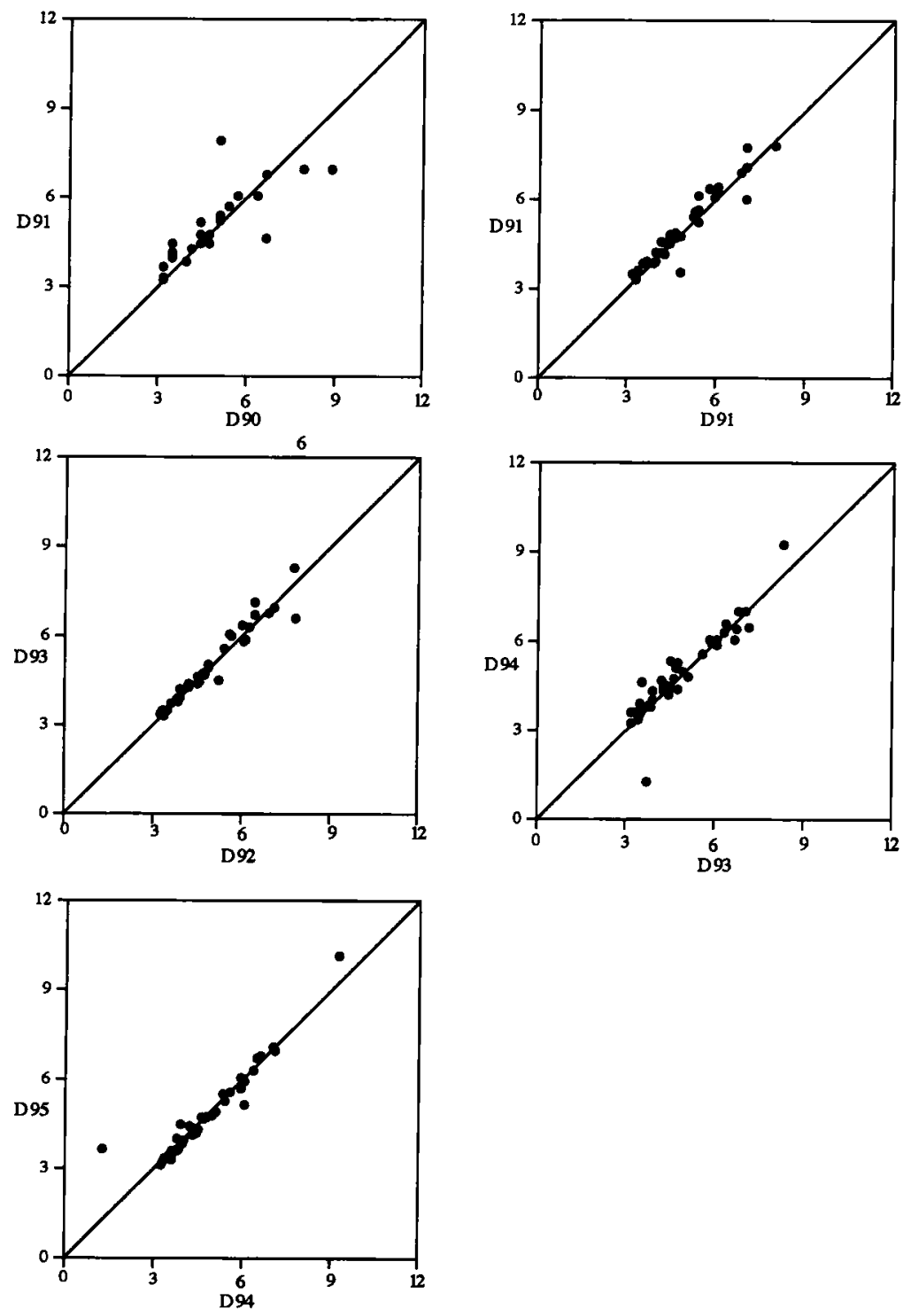

FIGURE 4. Yearly changes in diameter at breast height for Rinorea sp. from Fonseca.

species Vochysia ferruginea for both sites. This was one of only two species that was not characterized by massive resprouting after the hurricane, but one that was extensively represented as seedlings and small saplings. It is well-known in the area as a common member of old growth forests. Its growth rate seems not to have undergone the same extent of reduction as $G$. meiantha (Fig. 2) or $C$. smithianus (Fig. 4) in the post-hurricane years.

Applying regression analysis (with intercept set at zero, as explained above) to each species at both sites for each of the one-year growth periods from
1990 through 1995, we obtain estimates of the average yearly growth rate for each of the 18 species, as displayed in Figures 6 and 7. In both figures one can seemingly recognize two "guilds," one in which growth rates remain low during the entire period, and one in which growth rates are high immediately after the hurricane but gradually decrease as the canopy fills up. One species exhibited growth rates which remained relatively high during the entire post hurricane period.

A further pattern is evident from Figures 6 and 7. Fonseca is near the edge of the hurricane damage 

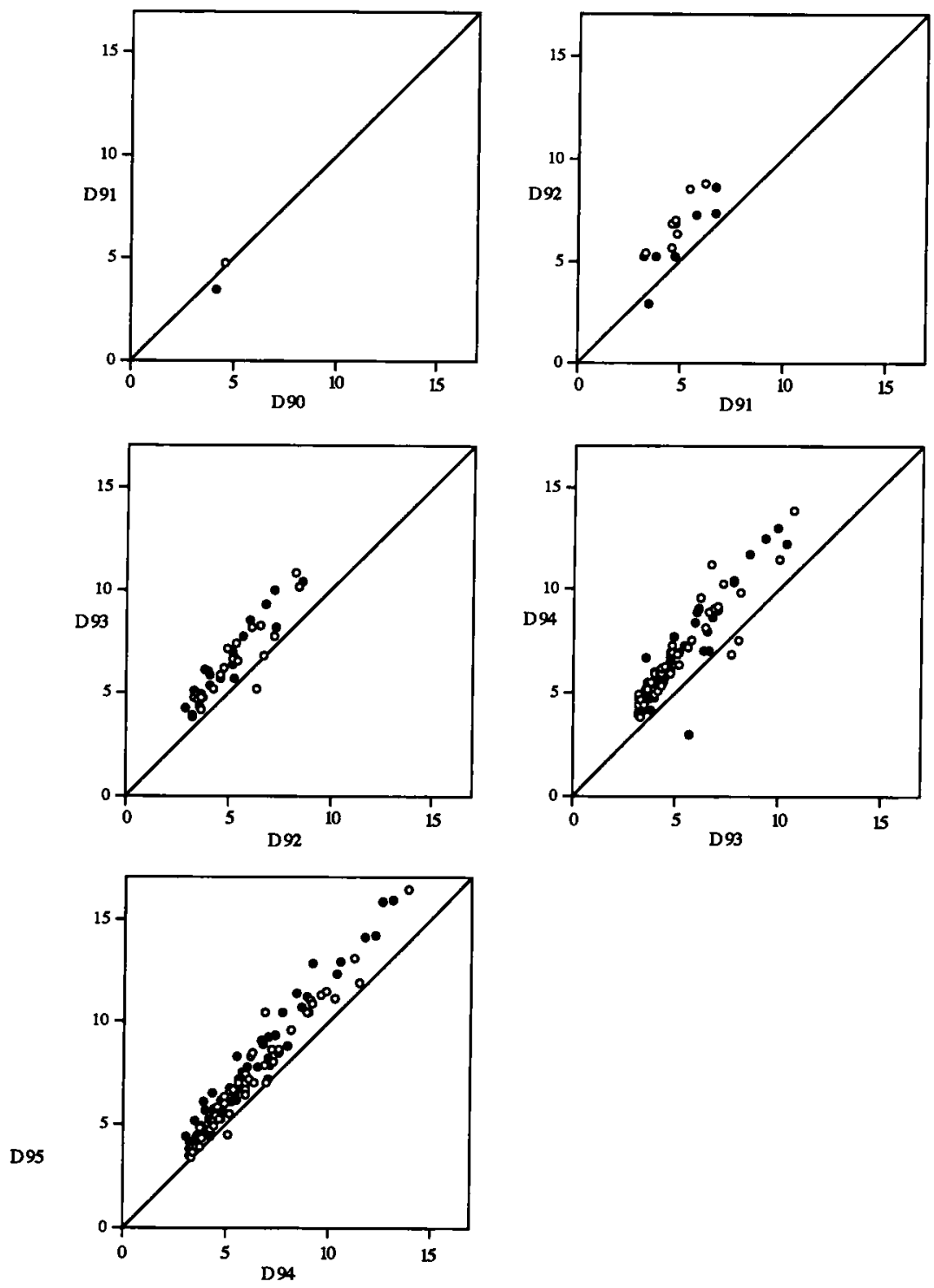

FIGURE 5. Yearly changes in diameter at breast height for Vochysia ferruginea from both sites (open circles from Fonseca, closed circles from Bodega).

zone while Bodega lies exactly in the middle of the zone. It is evident that the reduction in growth rates in Fonseca has progressed to the point that the fast-growing species have already reached the point of very slow growth associated with a completely filled canopy, while the reduction in growth rates in Bodega has not yet reached that point.

\section{DISCUSSION}

From the above data it would appear that there exist at least two distinct establishment/regeneration niches in the post hurricane environment-fastgrowing heliophytes (Croton, Guatteria, Isertia, Miconia, Byrsonima, Vismia, Cecropia, Goethalsia) and slow-growing "resprouters" (Cupania, Dendropanax, Rinorea, Casearea, Lacistemma, Pseudolmedia, Qualea, Galipea, and Manilkara).

For the most part the fast-growing heliophytes did not arrive immediately after the hurricane, but rather became common (in the category that we measured) only two years later. While Croton specifically was quite common in both sites in 1990 , its growth rate between 1990 and 1991 was so er- 


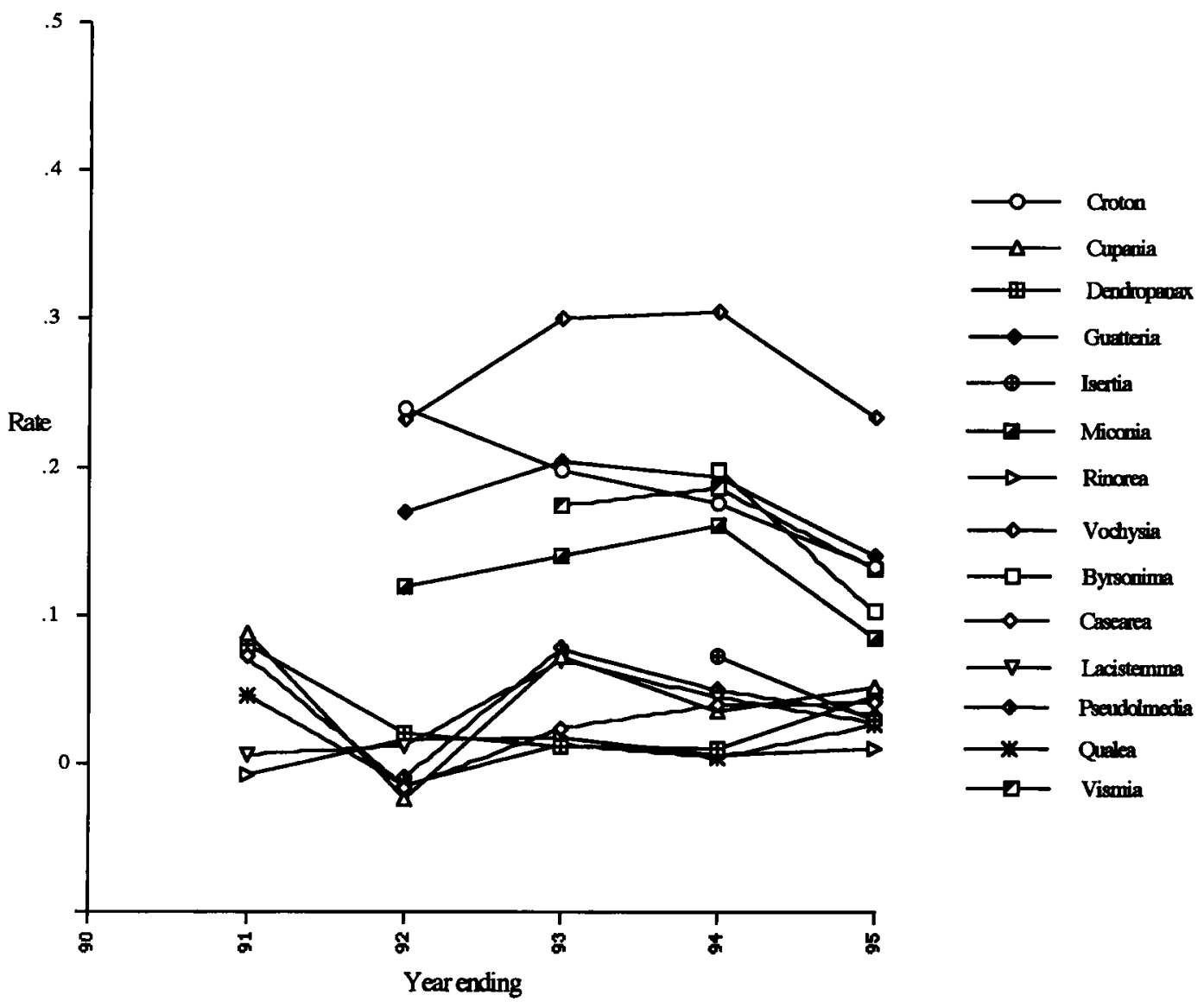

FIGURE 6. Relative growth rates (change in diameter at breast height as a fraction of original diameter at breast height) for five one year intervals subsequent to Hurricane Joan, at Bodega.

ratic that the regression was not significant for the first year (thus it is not plotted in Fig. 5). Goethalsia, the other wind-dispersed species, appeared immediately after the hurricane and fell into the typical heliophyte pattern. All other heliophytes, all bird dispersed, did not arrive in abundance until 1991 or later.

The slow-growing resprouters effectively remained in place after the hurricane, in a variety of different patterns (Vandermeer et al. 1995). Some are now large saplings or small trees grown from former branches of fallen or severely bent trunks. Others are relatively large-trunked individuals but with a newly sprouted canopy. Some are former large saplings that withstood the damage of the hurricane. Some are root sprouts from felled or severely truncated individuals. In all cases, they seem to have been present at the time the hurricane struck, withstood the damage, and remain growing very slowly. In all cases we have little evidence that they responded to the light "bath" provided by the hurricane, since their growth rates have remained effectively constant for the six post-hurricane years. They are the core of what we have referred to elsewhere as direct regeneration (Yih et al. 1991, Vandermeer et al. 1990).

Vochysia ferruginea seems to be in a category by itself, in that its average growth rate has not fallen significantly over the past six years. This may be due to the fact that the saplings grew so rapidly that they effectively became emergents with respect to the current dense low canopy (the canopy that currently exists at about 8-10 m). Thus, on average, they are capable of maintaining such high growth rates. Initial light measurements (unpublished data) suggest that this may be the case. The species is also an important timber species in the area, frequently dominating local forests. It is not one of the higher quality woods, but when forests are logged, it is normally taken along with more 


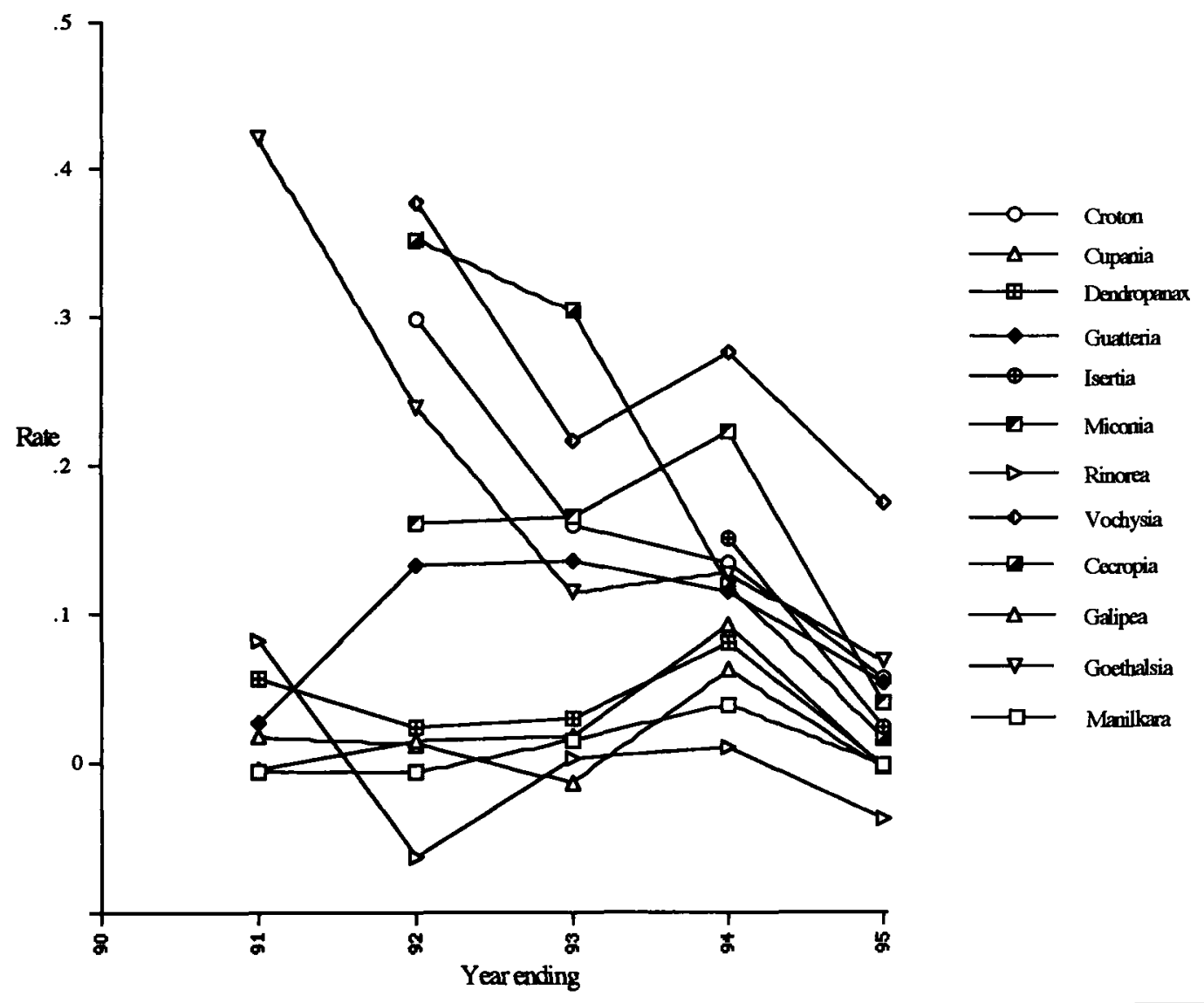

FIGURE 7. Relative growth rates (change in diameter at breast height as a fraction of original diameter at breast height) for five one-year intervals subsequent to Hurricane Joan, at Fonseca.

valuable species such as Carapa guianensis, Swietenia macrophylla, and Dalbergia retusa. According to local informants, it actually accounts for as much as $70 \%$ of the trunks taken out of these forests in the past $50 \mathrm{yrs}$, despite the fact that it is not a favored timber species. As an adult it has an apparently unique response to hurricanes, in that it appears to be incapable of resprouting after damage (Boucher et al 1994).

With the above categorization it is tempting to refer to the heliophytes simply as "second growth" species. Such an appellation would be misleading. In surveys of nearby second growth at both sites (Vandermeer et al. 1995), we found that the species inhabiting true second growth areas (i.e., areas that had been cleared for agriculture before the hurricane struck) were distinct from most of the species found in the hurricane damaged forest. Thus the heliophyte guild mentioned above is distinctive to a regenerating forest and is quite distinct from what might be called secondary vegetation.

This leads to the following general interpretation of forest dynamics in the face of disturbance. We hypothesize that there are four major guilds that need to be considered, based on response to the increased light regime found in the post hurricane forest: (1) fast-growing subcanopy trees (Croton, Guatteria, Isertia, Miconia, Cecropia, Byrsonima, and Vismia), (2) fast-growing canopy trees (Goethalsia, and Vochysia), (3) slow-growing subcanopy trees (Cupania, Galipea, Casearea, Lacistemma, and Pseudolmedia), (4) slow-growing canopy trees (Dendropanax, Rinorea, Manilkara, and Qualea). With the intense damage done by the hurricane, there is a tremendous potential for the entire area to be taken over by massive vine growth, potentially choking out much of the advanced regeneration. The rapid growth of categories 1 and 2 , 
mainly from sprouts and previously existing saplings, quickly establishes a dark canopy that retards the growth of climbers. Furthermore, the diffuse shade formed by the scattered larger resprouting individuals aids in retarding the vine growth. Subsequent growth of categories 3 and 4 is thus protected from vine growth by the rapid formation of this canopy. However, once the low canopy is fully formed and the thinning stage of succession begins, the smaller fast-growing species lose the advantage their fast growth had afforded them previously, and they begin to be overtopped by the two categories of canopy species. They thus tend to be thinned at a faster rate than the other three categories. Since both slow-growing categories are more capable of withstanding the low light levels of a typical understory, their thinning rates will be lower. In the short term (say 30 years), the forest is likely to become dominated by species in category 2 (fastgrowing and large). Over the long term it rather depends on how frequent such disturbances are. If no further catastrophic disturbance occurs, we expect the forest to be eventually dominated by the category 3 and 4 species with light gaps containing categories 1 and 2, depending on their age. The canopy, of course, will be dominated by the category 2 and 4 species because of their size.

\section{ACKNOWLEDGMENTS}

This work was supported by NSF BSR-8917688, and a grant from the Office of the Vice-President for Research at the University of Michigan, both to John Vandermeer. Data gathering and intellectual input were provided by (among others) Ivette Perfecto, María Antonia Mallona, Milton Castrillo, Jerry Urquart, Ray Garth, and Ernesto Lemos. Nelson Zamora provided the initial identification of all specimens.

\section{LITERATURE CITED}

Boucher, D. 1992. En la Costa, un huracán cada siglo. Wani (Managua) 12: 32-34.

Boucher, D., J. H. Vandermeer, M. A. Mallona, N. Zamora, and I. Perfecto. 1994. Resistance and resilience in a directly regenerating rainforest: Nicaraguan trees of the Vochysiaceae after hurricane Joan. J. of For. Ecol. 68: $127-136$.

Brokaw, N. V. L., aNd J. S. Grear. 1991. Forest structure before and after Hurricane Hugo in Luquillo Experimental Forest, Puerto Rico. Biotropica, 23: 386-392.

Canham, C. D., and O. L. Loucks. 1984. Catastrophic windthrow in the presettlement forests of Wisconsin. Ecology 65: 803-809.

Chesson, P. L., AND R. R. WARner. 1981. Environmental variability promotes coexcistence in lottery competitive systems. Am. Nat. 117: 923-943.

Dunn, C. P., G. R. Guntenspergen, and J. R. Dorney. 1983. Catastrophic wind disturbance in an old-growth hemlock-hardwood forest, Wisconsin. Can. J. Bot. 61: 211-217.

Flanagan, M. 1988. The damage caused by the hurricane force winds to the trees at the Royal Botanic Gardens, Kew. Arboriculture Journal 12: 181-188.

Frangl, J. L., AND A. E. Lugo. 1991. Hurricane damage to a flood plain forest in the Luquillo mountains of Puerto Rico. Biotropica, 23: 324-335.

GRUBB, P. J. 1977. The maintenance of species-richnss in plant communities: the importance of the regeneration niche. Biol. Rev. 52: 107-145.

Hubbell, S. P., and R. B. Foster. 1986. Biology, chance, and history and the structure of tropical rain forest tree communitiees. In J. Diamond and T. J. Case (Eds.). Community ecology, pp. 314-329. Harper and Row Publishers Inc., New York, New York.

MILLER, T. E. 1982. Community diversity and interactions between the size and frequency of disturbance. Am. Nat. 120: $533-536$.

Mooney, Harold A., and M. Gordon. (Eds.) 1983. Disturbance and ecosystems. Springer-Verlag, Berlin.

Pickett, S. T. A., AND P. S. White. (EDs) 1985. Natural disturbance and patch dynamics. Academic Press, New York.

REILLY, A. E. 1991. The effects of Hurricane Hugo in three tropical forests in the U. S. Virgin Islands. Biotropica, 23: $414-419$.

Silvertown, J., AND R. LAw. 1987. Do plants need niches? Some recent developments in plant community ecology. Trends Ecol. Evol. 2: 24-26.

SousA, W. P. 1984. The role of disturbance in natural communities. Ann. Rev. Ecol. Syst. 15: 353-391.

SPURR, S. H. 1956. Natural restocking of forests following the 1938 hurricane in central New England. Ecology 37: $443-451$.

VAndermeer, J. H. 1994. Disturbance and neutral competition theory in rain forest dynamics. Ecol. Modelling 85: 99-111.

Vandermeer, J. H., N. Zamora, K. Yih, and D. Boucher. 1990. Regeneración inicial en una selva tropical en la costa caribeña de Nicaragua después del huracan Juana. Revista Biología Tropical (Costa Rica) 38: 347-359.

Vandermeer, J. H., M. A. Mallona, D. Boucher, I. Perfecto, and K. YiH. 1995. Three years of ingrowth following 
catastrophic hurricane damage on the Caribbean Coast of Nicaragua: evidence in support of the direct regeneration hypothesis. J. Trop. Ecol. 11: 465-471.

WALKR, L. R. 1991. Tree damage and recovery from Hurricane Hugo in Luquillo Experimental Forest, Puerto Rico. Biotropica 23: 379-385.

YiH, K., D. H. Boucher, N. Zamora, And J. H. Vandermeer. 1991. Recovery of the rain forest of southeastern Nicaragua after destruction by Hurricane Joan. Biotropica 23: 106-113. 